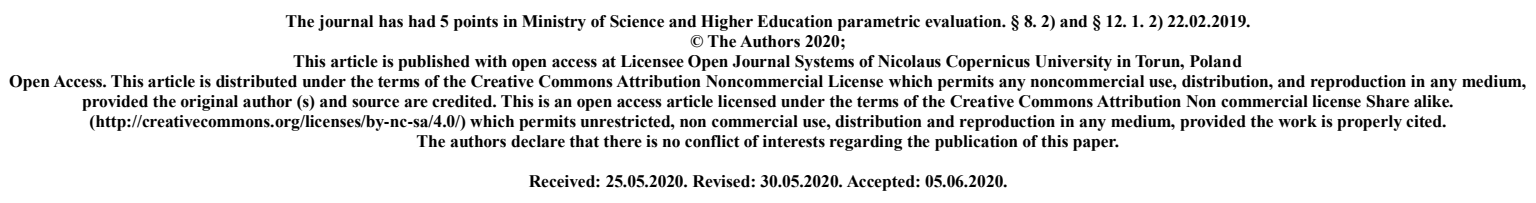

\title{
Student's knowledge of obesity at the Collegium Medicum of the Jan Kochanowski University in Kielce
}

\author{
Kamil Redziak
}

ORCID: https://orcid.org/0000-0001-8890-9160

e-mail: kamilredziak@o2.pl

Collegium Medicum, The Jan Kochanowski University in Kielce

Aleja IX Wieków Kielc 19A, 25 - 317 Kielce

\section{SUMMARY}

Introduction: Obesity is considered to be an epidemic of the XXI century. According to the World Health Organisation (WHO), the number of overweight people aged 18 and over in 2016 was 1.9 billion, 650 million of whom were obese. The causes of obesity are mainly due to erroneous eating habits and low levels of physical activity. Obesity is a disease, but it is also a factor causing many diseases, including chronic diseases that can lead to disability and premature death.

Aim: The aim of the study was to assess the level of knowledge of students of the Faculty of Medicine and Health Sciences of Jan Kochanowski University in Kielce about the causes and effects of obesity.

Material and methods: In this work, we used a self-assessment questionnaire to conduct the research. The survey was conducted among students of Collegium Medicum of Jan Kochanowski University in Kielce. The research group consisted of 111 students, including 98 students and 13 students. The respondents lived in both urban and rural areas.

Results: The analysis of the collected data shows that the students have knowledge about obesity, know the causes, health effects and show that extensive preventive actions will contribute to reduce the incidence of obesity. 
Conclusions: Students have a high knowledge of obesity, correctly identifying the causes and methods of diagnosis of obesity. They also have sufficient knowledge of the impact of obesity on health.

Key words: obesity, causes, epidemiology, health effects.

\section{Introduction}

Obesity is considered to be an epidemic of the 21 st century. It affects a growing number of people, mainly in developing and highly developed countries, and is one of the causes of mortality and many diseases, as well as being a burden on the budgets of most countries in the world. Obesity is a chronic metabolic disease, which is a result of energy homeostasis disorders. It is the primary cause of increased accumulation of adipose tissue in the body; over time and as the amount of adipose tissue increases, pathologies and dysfunctions appear, which in fact affect almost all systems and organs [1]. Obesity is a condition characterized by gradual increase in body weight due to excessive accumulation and increase in body fat (in men - more than $25 \%$ and in women - more than $30 \%$ of body weight) resulting from hyperplasia and/or hypertrophy of adipocytes, i.e. fat cells [2]. This results in the occurrence of many diseases which persist for a long time despite the reduction of body mass.

The phenomenon of overweight and obesity currently has an upward trend not only in Poland, but also in Europe and the USA. The largest percentage of obese people are aged 20-50 years. After 60 years of age this percentage is decreasing [3]. According to the World Health Organization (WHO), the number of overweight people, aged 18 years and over, in 2016 was 1.9 billion, 650 million of whom were obese. Between 1975 and 2016, the number of people with obesity tripled. Worldwide, $13 \%$ of the population (15\% women and $11 \%$ men) are obese. Moreover, as many as 38.2 million children under the age of 5 were overweight or obese in 2019. And the number of overweight or obese people in the 5-19 age group was 340 million. In addition, as in adults, the number of overweight people between the ages of 5-19 increased appallingly. In 1975, the number of children and adolescents with obesity was less than $1 \%$ and in 2016 , obesity was already $8 \%$ of boys and $6 \%$ of girls, which gave the number 124 million [4].

The factors contributing to overweight and obesity are environmental, pharmacological, psychological and biological factors. These factors are interdependent; however, genetic factors constitute up to $40 \%$ of the causes of these disorders. The remaining $60 \%$ are mainly environmental factors, which are usually subject to modification [3].

Environmental factors include poor nutrition and low levels of physical activity. Technological progress in recent years has contributed to a significant reduction in energy expenditure associated with, among other things, daily physical activity, which results in a positive energy balance, characterized by the fact that the amount of energy supplied to the body is greater than its energy requirements, resulting in an increase in body weight. This state, which persists for a long time, leads to overweight and obesity. It is also worth paying attention to the quality of food consumed during the day. At the same time as technological progress, access to food has become easier, which resulted in increased food consumption. The food we eat contains large amounts of fat and easily assimilable carbohydrates (sucrose, simple sugars, rapidly digested and absorbed starch). Greasy foods are preferred because of 
their higher organoleptic qualities (e.g. taste, smell), which contributes to their increased consumption. Another nutritional mistake is the consumption of large quantities of sweet drinks, causing a feeling of satiety after drinking them, and a rapid flow from the stomach to further stretches of the gastrointestinal tract, which makes it easy to absorb the carbohydrates contained in them. Eating habits are mainly shaped by family, school and media advertising. The latter often encourage us to consume fast-food, sweet and salty snacks and sweetened drinks. A high-fat and high-calorie diet, and at the same time poor in fruit, vegetables, micro and macroelements and vitamins is responsible for the spread of overweight and obesity. Sedentary lifestyles, automation and generally decreasing levels of physical activity of societies combined with excessive food consumption are conducive to the development of obesity not only in developed but also in developing countries. It is suspected that in today's society the level of physical activity is much lower than that of our great-grandfathers in the Palaeolithic era. In the latter, it is estimated that the loss of energy resulting from physical activity alone was in the region of $1000 \mathrm{kcal}$ per day, with $3000 \mathrm{kcal}$ supplied daily with food, giving a 1:3 energy balance ratio in favour of energy supplied with food. Nowadays, when most of us have a sedentary lifestyle, we use about $300 \mathrm{kcal}$ per day for physical activity, and assimilate about $2100 \mathrm{kcal}$ per day with meals, which gives a ratio of 1:7. In the 1970s and 1990s the growth curve of the number of obese people was directly proportional to the curve of cars sold and the average number of hours spent in front of the television during the day. The reduction in physical activity may also be secondary, resulting from the obese person's difficulty in moving, which in turn contributes to further weight gain and the vicious circle closes [5]. All activities requiring movement are increasingly often performed by electronic equipment. We move less and less every day and become more and more sluggish. Our muscles are not engaged in energy-intensive work, frankly speaking, we go for the so-called "easy way" [6].

A different group of factors are genetic factors which, unlike environmental factors, are not susceptible to modification. Clinical observations, indicating a higher incidence of obesity in children of overweight parents than in children with normal body weight, prompted researchers to search for obesity genes. Nowadays, it is known that normal body weight is to a large extent conditioned by multiple factors and obesity may result from disturbances in the functioning of weight-control genes by influencing proper thermogenesis, fat metabolism and accumulation, as well as maintaining an appropriate amount of adipocytes, etc. The realization of genetically conditioned susceptibility to obesity is subject to environmental influences - in conditions of easy access to food and restriction of physical activity, the expression of weight-controlling genes leads to obesity. Environmental influences are likely to be strongest in childhood, when eating habits are formed, usually in accordance with the parents' habits. Today, several dozen genes have been isolated, which may play a role in obesity development. The best known is the $o b$ gene located on the seventh chromosome. Its product is leptin, a protein produced by adipose tissue, which reaches the hypothalamus with blood, where it then binds to the receptor, as a result of which the synthesis and release of neuropeptide $\mathrm{Y}$, which increases the demand for food and reduces thermogenesis, is inhibited. Leptin increases the sense of satiety, decreases appetite and enhances thermogenesis, which increases energy consumption and decreases the concentration of insulin and glucose in blood [7]. 
Obesity is a disease, but it is also a cause of many diseases, including chronic diseases that can lead to disability and premature death. Obesity is compounded by the occurrence of many ailments, these are primarily diseases of the cardiovascular system, the respiratory system, metabolic disorders, cancer, dysfunction of the gastrointestinal and genitourinary tract, as well as the skeletal-articular system. Obesity also negatively affects our mental health.

Cardiovascular diseases are the main cause of mortality in Poland. Numerous epidemiological studies have shown that BMI correlates with the increase in cardiovascular diseases, as the risk of death due to these diseases increases. Excessive mortality in obese individuals results, among others, from significantly higher incidence of cardiovascular diseases: arterial hypertension, atherosclerosis, ischaemic heart disease, stroke, pulmonary embolism, and lower limb varices [8].

Abnormalities in the cardiovascular system are most often caused by inappropriate lipidogram - increased cholesterol concentration, especially LDL cholesterol (LDL- low density lipoproteins), low HDL cholesterol (HDL- high density lipoproteins), as well as increased triglyceride concentration. Other relevant disorders include hypertension, impaired glucose tolerance, abdominal obesity, increased blood homocysteine levels, increased lipoprotein A concentration and low consumption of oxidative components [9]. Elevated lipidogram induces arteriosclerosis, including coronary arteries, the blockage of which leads to ischaemic heart disease, which in turn causes myocardial infarction, i.e. a life-threatening condition. Obesity causes heart fat. It is not uncommon that adipose tissue accounts for $50-60 \%$ of the total weight of this organ. This phenomenon, in turn, causes myocardial hypertrophy and, consequently, myocardial insufficiency. The excess of adipose tissue also contributes to the reduction of circulating blood in relation to body weight as well as its density. This contributes to an increase in blood viscosity and changes the conditions of its flow through the capillaries. Increased peripheral resistance causes the sequence of haemodynamic adaptation processes, which may include overload and hypertrophy of the left ventricle and increased systolic blood pressure [10].

Moreover, obesity is a part of the so-called fatal quartet, i.e. four cardiovascular risk factors: lipid disorders, hypertension, glucose intolerance, central type obesity [11]

An early symptom of respiratory distress is exercise dyspnea, which can be caused by reduced chest dilatation and impaired diaphragm mobility. This can even develop into a disorder called follicular hypoventilation. Such obesity syndromes with gas exchange disorders used to be called "Pickwick's syndrome". The spirometry test in obese individuals is used to diagnose significant ventilation disorders. The diagnosis of vesicular hypoventilation is determined by gasometry. This syndrome is distinguished by: excessive obesity with symptoms of outstanding sleepiness, cyanosis, muscle tremor, secondary redness, periodic superficial respiration, and left ventricular hypertrophy with accompanying in the final stage of cardiac insufficiency. It is also established that oxygen saturation in blood is reduced and $\mathrm{CO} 2$ retention is increased. This syndrome is constantly evolving and causes serious complications such as pulmonary heart, arterial hypertension and pulmonary embolism. Another important disorder is sleep apnea, which manifests itself in frequently repeated interruptions in the respiratory rhythm with loss of air supply to the lungs. There are usually five episodes of total or partial apnea per hour. It often awakens the patient from sleep at night and is a consequence of excessive sleepiness during the day. Initially, patients are only prone to 
snoring; over time, severe paroxysmal states of apnea occur, which contribute to disability and sudden deaths during sleep [1].

Cancer, in the health and social sense, is of great importance to society worldwide. Cancer is currently the second cause of death in Poland, just after cardiovascular diseases. The way in which overweight or obesity can affect the development of cancer is very heterogeneous. These mechanisms include: estrogen production, whose high level is correlated with an increased risk of hormonally dependent cancers (breast, uterine stem cancer), higher levels of insulin-like growth factor (IGF) increase the risk of liver cancer, non-Hodgkin's lymphoma (in men), bladder cancer and colorectal cancer (in women), increased production of adipokines, which regulate the growth of the cell's inflammatory processes, as well as altered immune response and oxidative stress. Obesity is also a very strong risk factor for the development of colorectal and breast cancer in postmenopausal women as well as in the uterus, stomach, liver, gall bladder, kidney and pancreas. Considering that the number of obese people worldwide is increasing, it is necessary to investigate as soon as possible and in detail the mechanisms linking obesity with an increased risk of developing cancer and to develop a strategy to prevent this phenomenon [12].

Excessive strain on the skeletal-articular system results in degenerative changes, which impair the motor activity, which results in pain, which intensifies when moving; therefore, obese people are willing to lead a sedentary lifestyle and lack of physical activity leads to increased obesity. The skeletal-articular system is distinguished by a certain plasticity. If the forces acting exceed the limit of adaptation, i.e. it is a long-term overload (such as excessive body weight), then degeneration and deformation of the bones and soft parts of the joint occurs. Obesity accelerates wear and tear on mainly the knee joints of the foot, hip and sacrum, hip and spine, mainly in the lumbar region. The observations of orthopaedists indicate that obesity may also cause the flattening of the knees or feet [10].

It is not only the causes of overweight and obesity that are complex, but also its effects on both physical, mental and social health. In addition to a number of health and physical complications, obesity can lead to serious emotional, mental and social problems. These include, among others: anxiety, shame, submissiveness, lowering self-esteem, lack of acceptance of one's appearance, alexiety, disturbances of one's own body image, self-respect, experiencing prejudice and discrimination and withdrawal from interpersonal contacts [13]. Due to the dependencies described above and the prevalence of this phenomenon, researchers are increasingly interested in the quality of life of overweight and obese people, and an indepth analysis of this issue may contribute to the development of methods to help reduce overweight and obesity. It may be particularly important to observe the relationship between the quality of life of obese people and such variables as mental health, social support and selfefficacy [14].

\section{Aim}

The aim of the study was to assess the level of knowledge of students of the Faculty of Medicine and Health Sciences of Jan Kochanowski University in Kielce on the causes and effects of obesity. 


\section{Material and methodology}

In the following work, a self-analysis questionnaire was used, which consisted of 30 questions, of which 23 were single-choice and 7 multiple-choice questions. The time for completing the questionnaire was unlimited. The survey was anonymous and voluntary. It was conducted in November 2017 among students of the Faculty of Medicine and Health Sciences (now Collegium Medicum) of Jan Kochanowski University in Kielce. The research group consisted of 111 students, including 98 female students and 13 students.

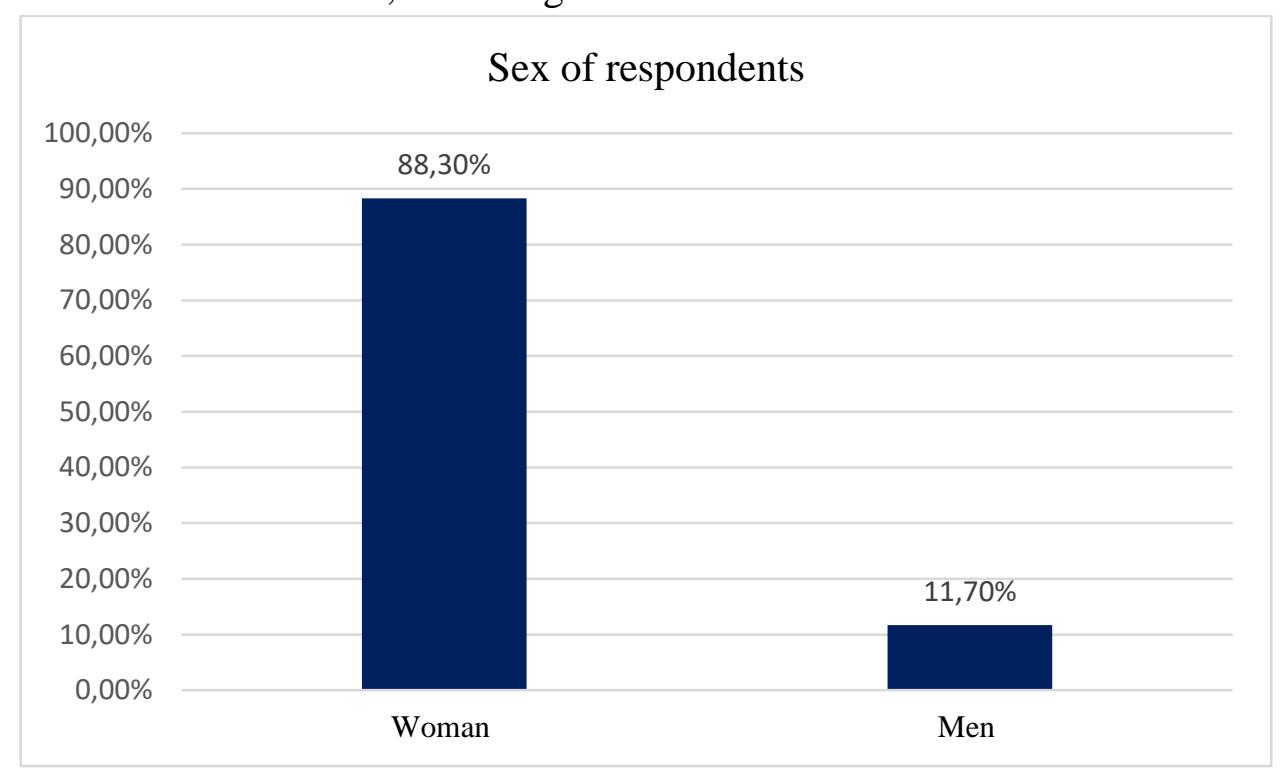

Figure 1. Gender of respondents.

98 (88.3\%) women participated in the anonymous survey, while the number of men participating in the survey was $13(11.7 \%)$.

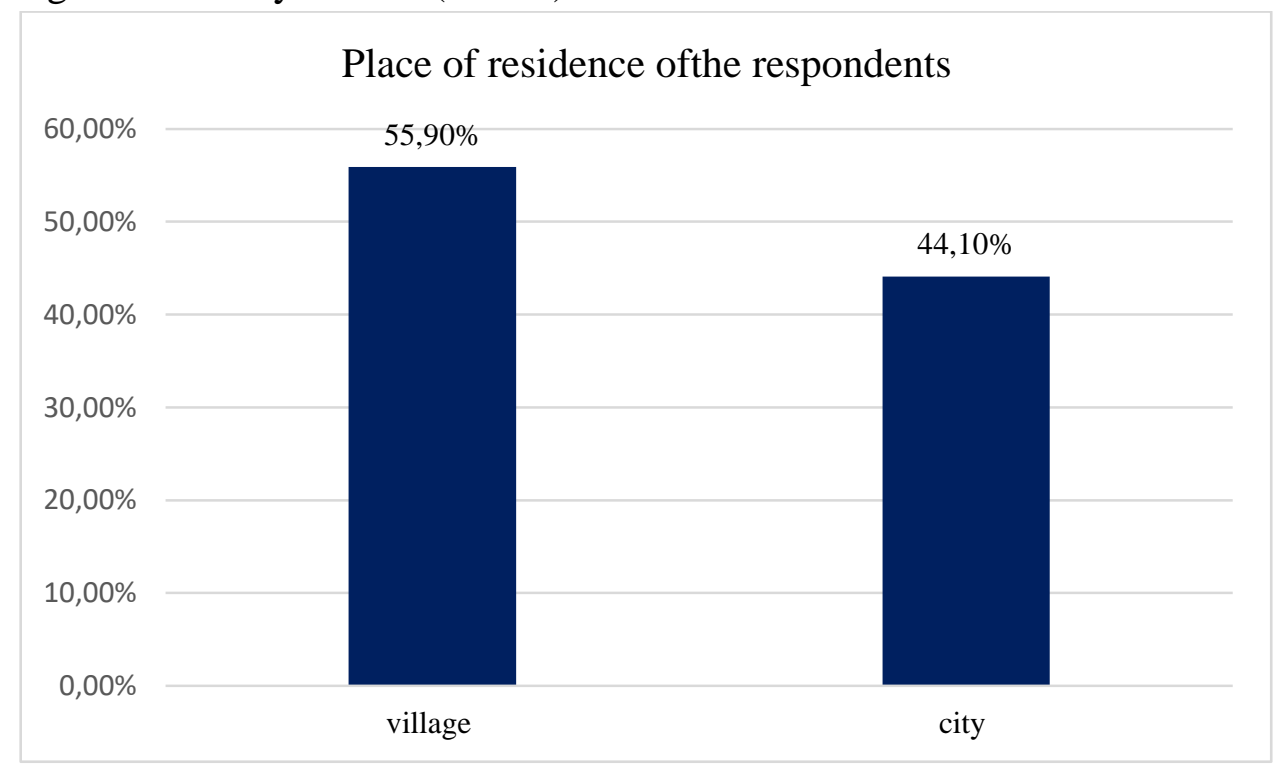

Figure 2. Residence of respondents

From the urban environment there were 49 respondents, i.e. $44.1 \%$, while from the rural environment there were 62 respondents, i.e. $55.9 \%$. 


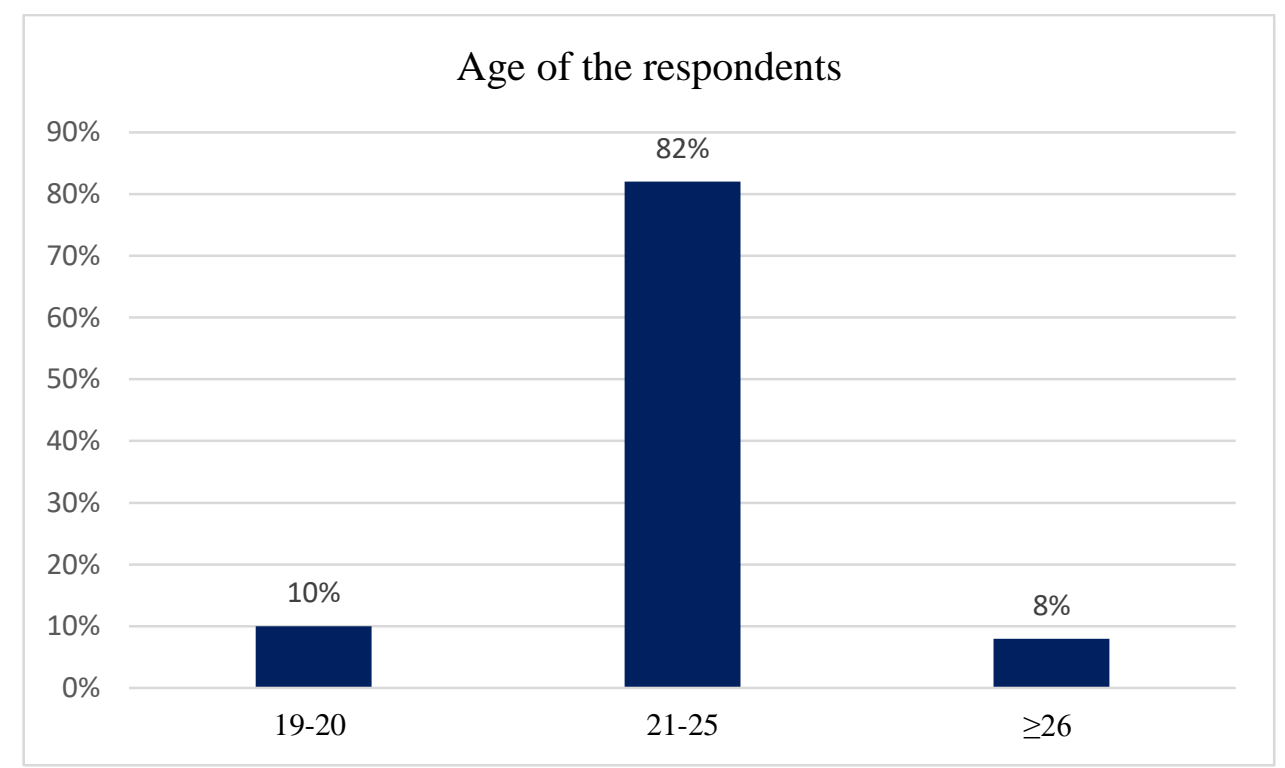

Figure 3. Age of respondents

The highest percentage of respondents - $82 \%$ (91 persons) were in the age range 21-25 years. On the other hand, in the 19-20 age group there were 11 people (10\%), and at the age of 26 or more there were $8 \%$ of the respondents, i.e. 9 people.

\section{Results}

In your opinion, we recognize obesity when the amount of body fat

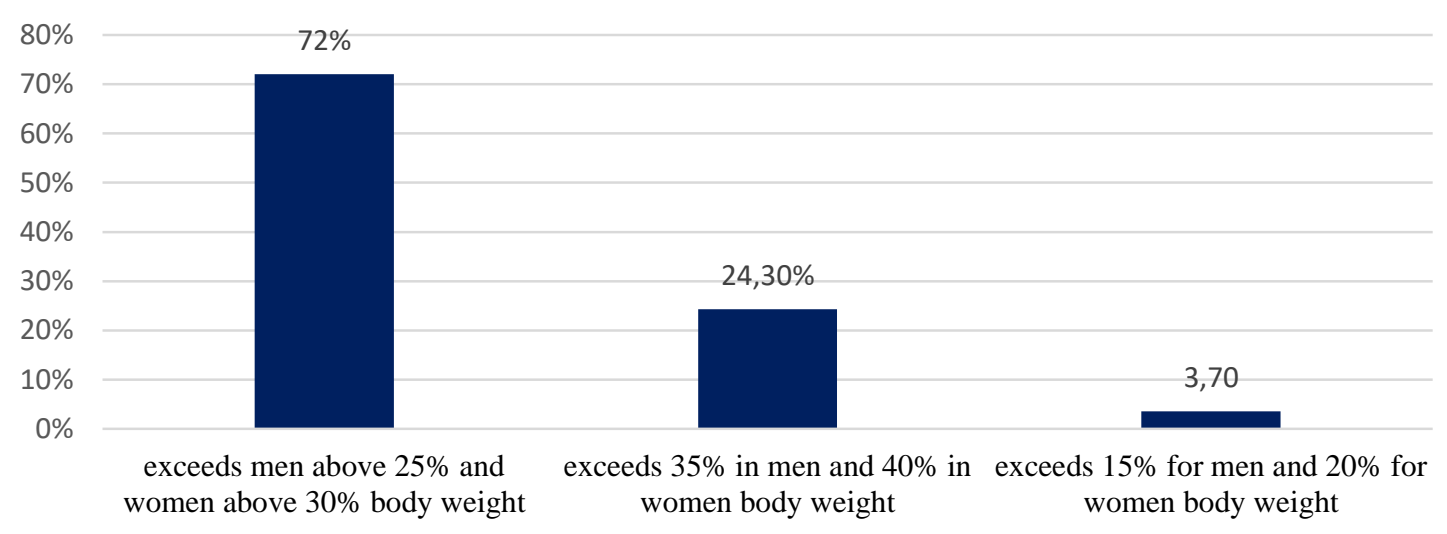

Figure 4. Students' knowledge of the percentage of body fat from which obesity is diagnosed. The majority of the examined persons - $72 \%$ indicated the answer that obesity is diagnosed if the body fat content exceeds $25 \%$ in men and $30 \%$ in women. The rest of the examined group $-28 \%$ indicated incorrect answers. 


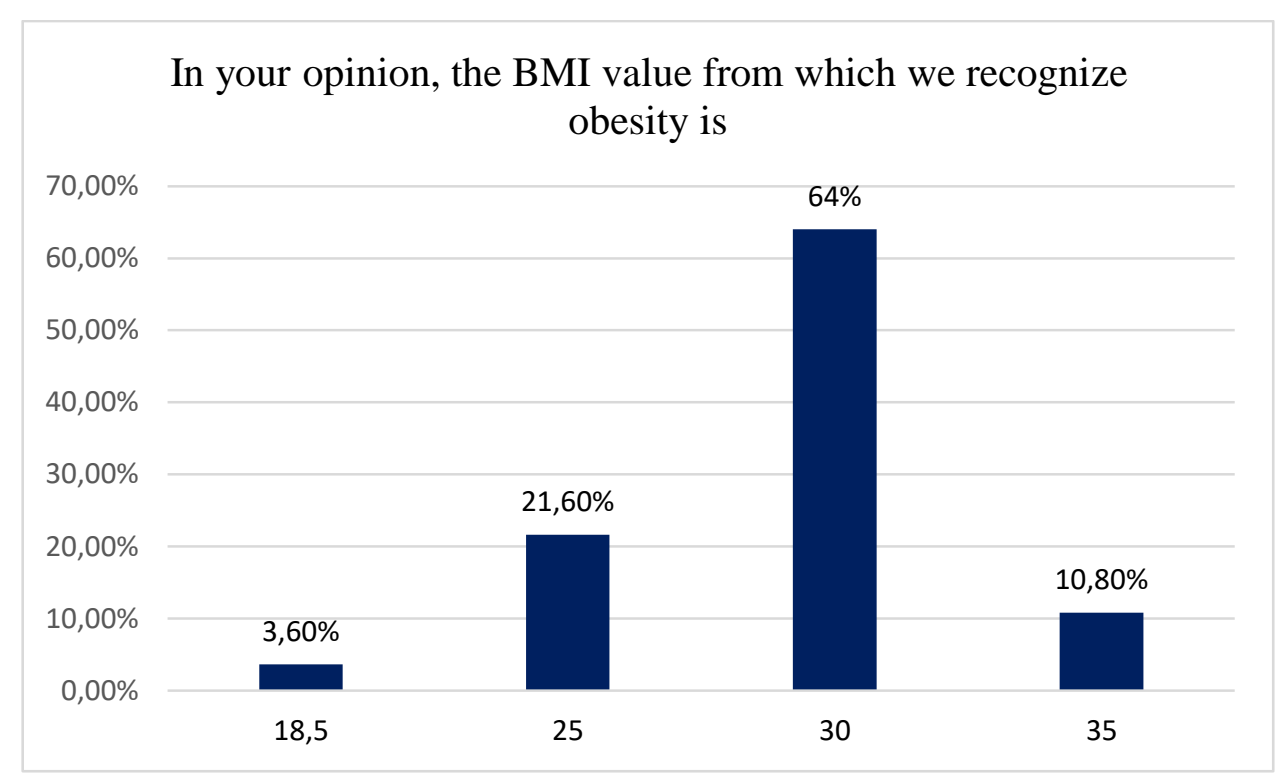

Figure 5. BMI value from which we recognize obesity

The majority of respondents - $64 \%$ indicated the correct answer, saying that the BMI value from which we recognize obesity is $30 \mathrm{~kg} / \mathrm{m} 2$. The rest of the examined group - $36 \%$ indicated wrong answers.

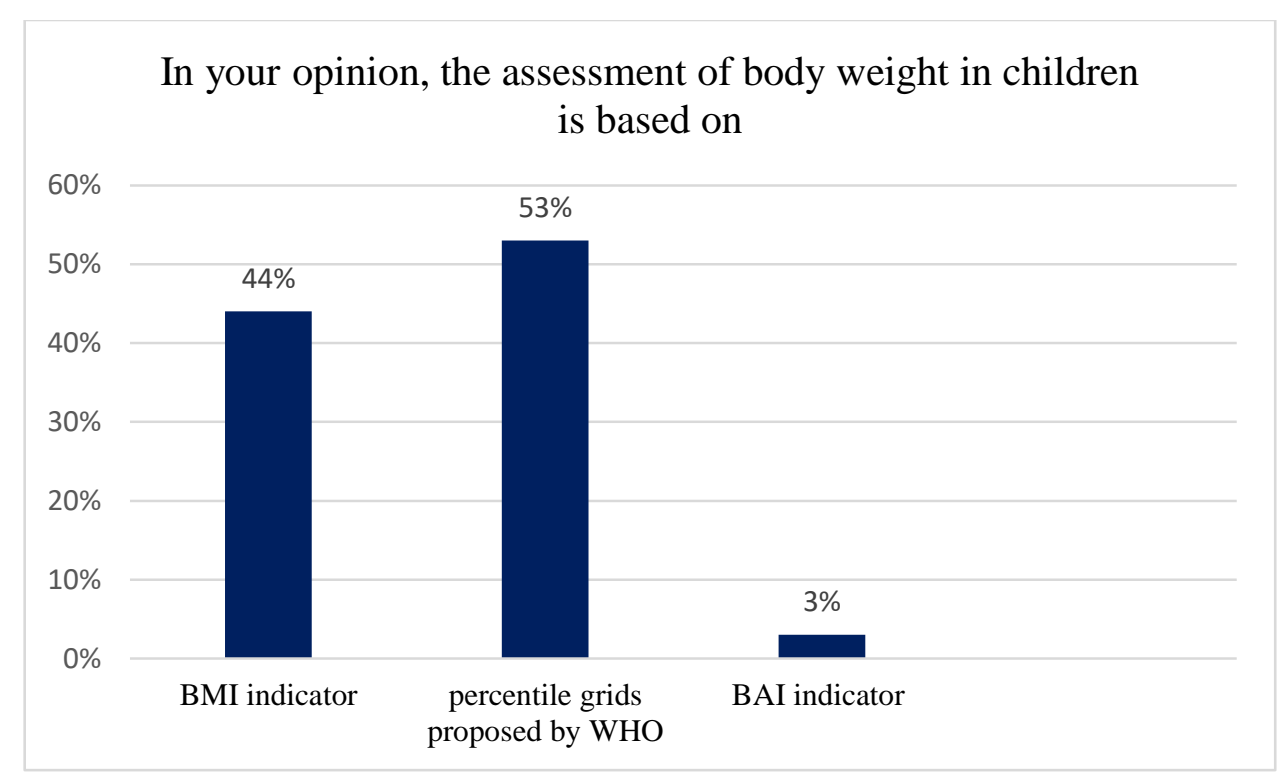

Figure 6. Methods of assessing body weight in children

Slightly more than half of the studied group - 53\% indicated that for the assessment of body weight the centile nets proposed by the WHO are used and this was the correct answer. The remaining part of the examined persons - $47 \%$ indicated incorrect answers. 


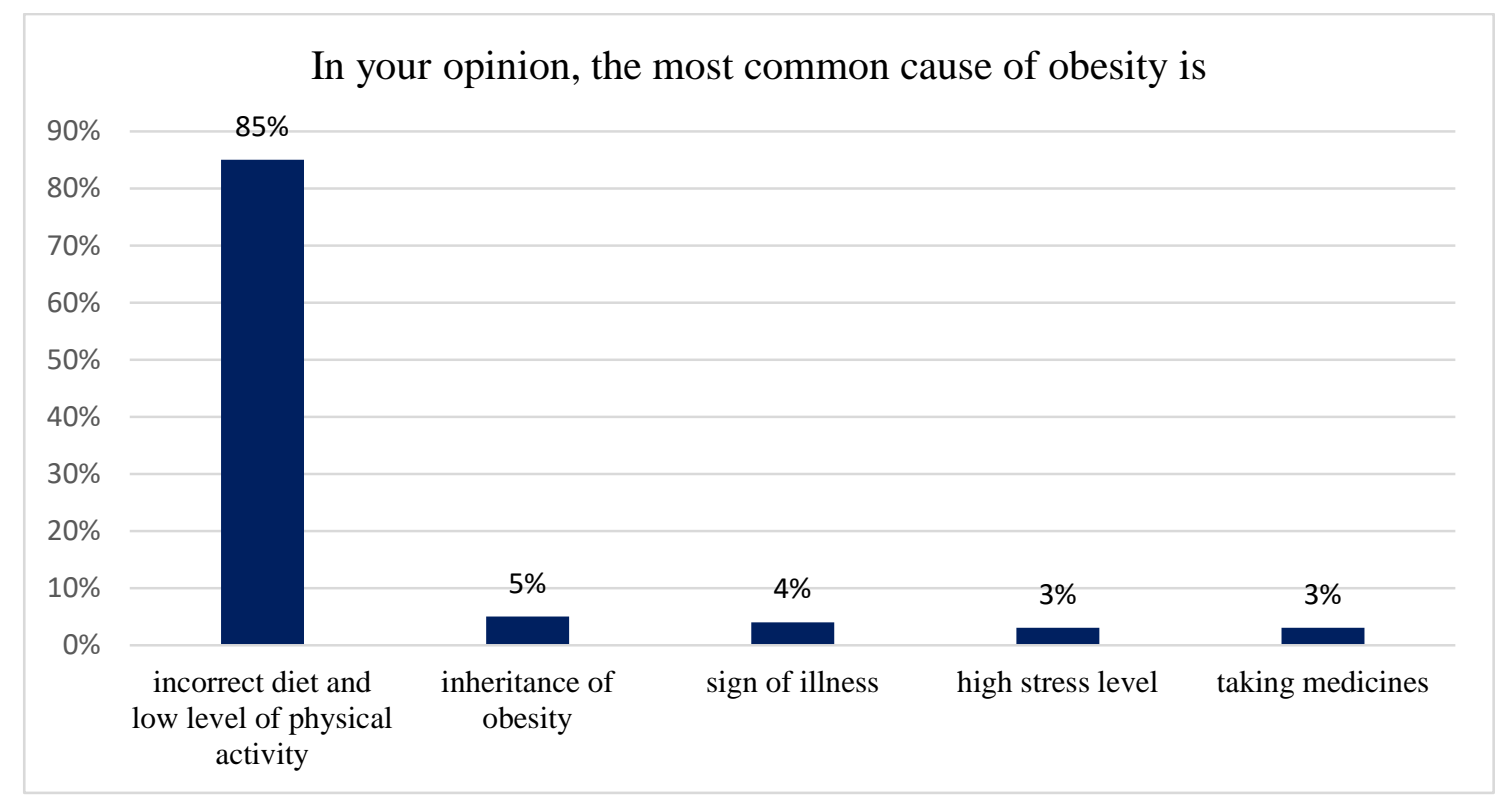

Figure 7. The most common cause of obesity

The highest percentage of the surveyed persons, amounting to $85 \%$, indicated that a wrong diet and low level of physical activity contribute the most to the occurrence of obesity, and this was the correct answer. The rest of the respondents indicated answers such as inheritance of obesity, sign of another disease, high level of stress and medication intake. These factors affect the incidence of obesity, but to a much lesser extent.

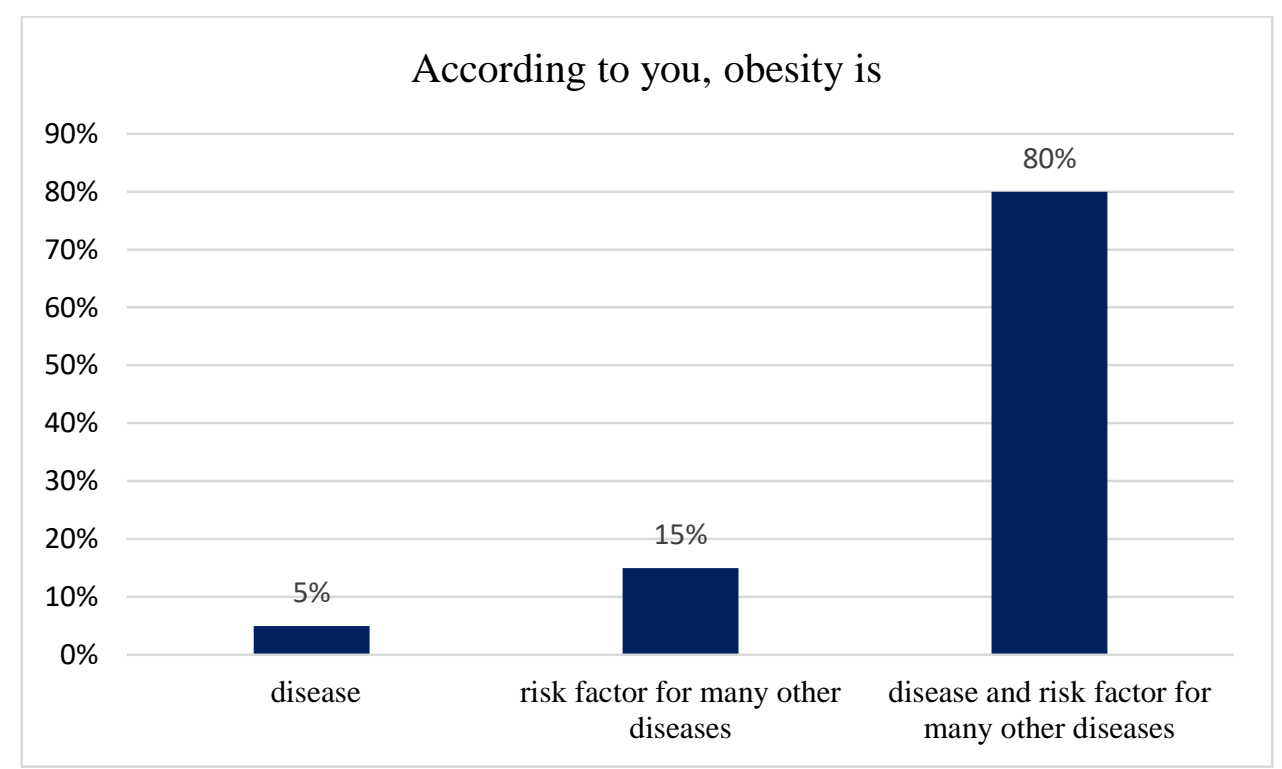

Figure 8 Perception of obesity

The vast majority of the examined persons - 80\% indicated the correct answer saying that obesity is a disease unit and at the same time a risk factor for many other diseases. The remaining $20 \%$ of the respondents indicated incorrect answers. 


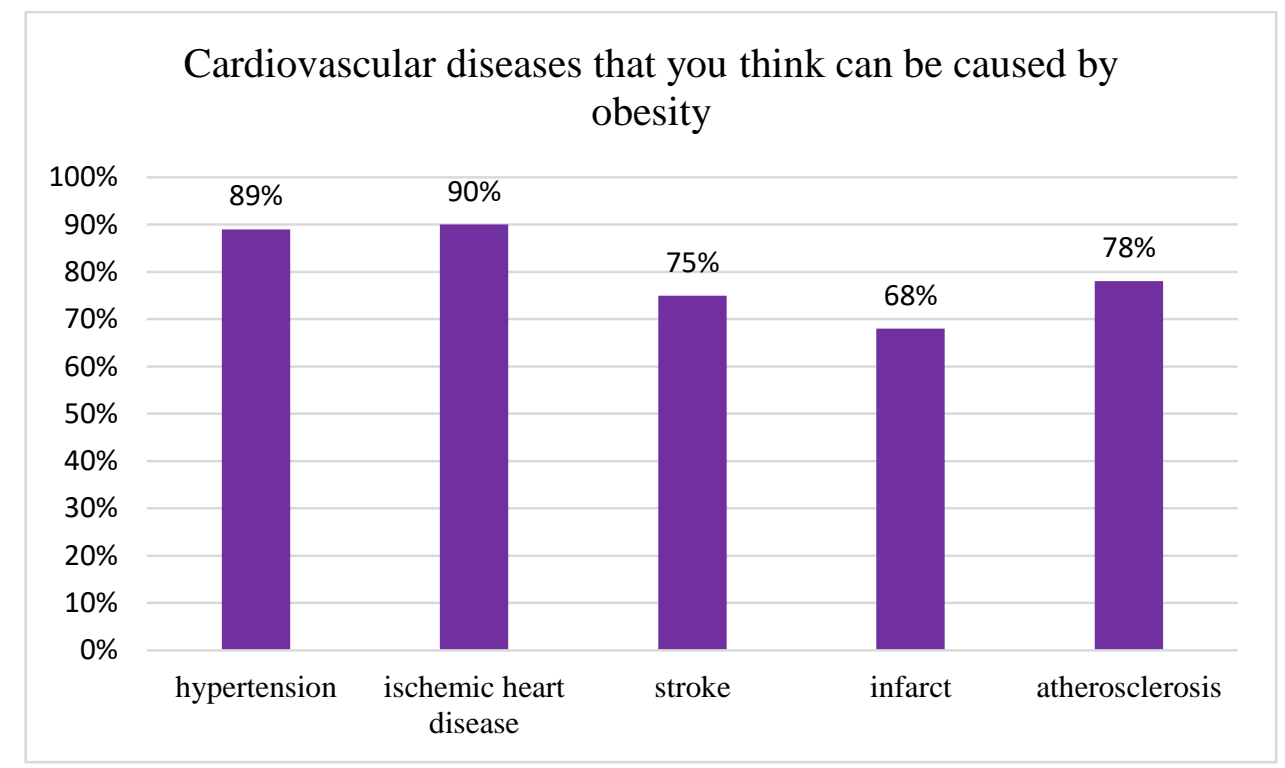

Figure 9. Cardiovascular diseases caused by obesity

The most frequently indicated disease units were arterial hypertension - 89\%, ischaemic heart disease $-90 \%$, atherosclerosis $-78 \%$. Of the proposed answers, all were correct. However, only $30 \%$ of the examined individuals indicated all answers, $20 \%$ four answers, $30 \%$ three answers and $20 \%$ two answers.

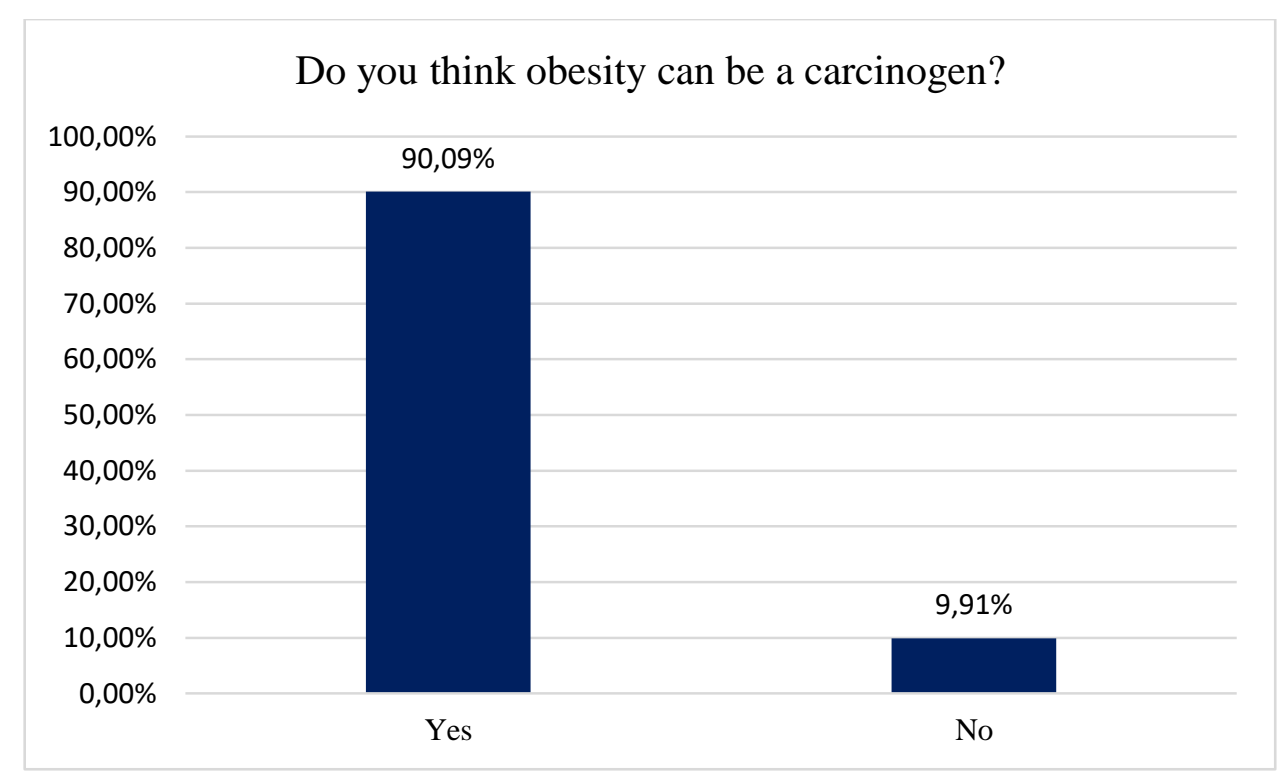

Figure 10. Obesity as a carcinogenic factor

According to the vast majority of respondents, $90.09 \%$ obesity is a carcinogenic factor, which is the correct answer. According to the rest of the respondents $-9.91 \%$ obesity does not contribute to the formation of cancer, which is obviously the wrong answer in the light of current medical knowledge. 


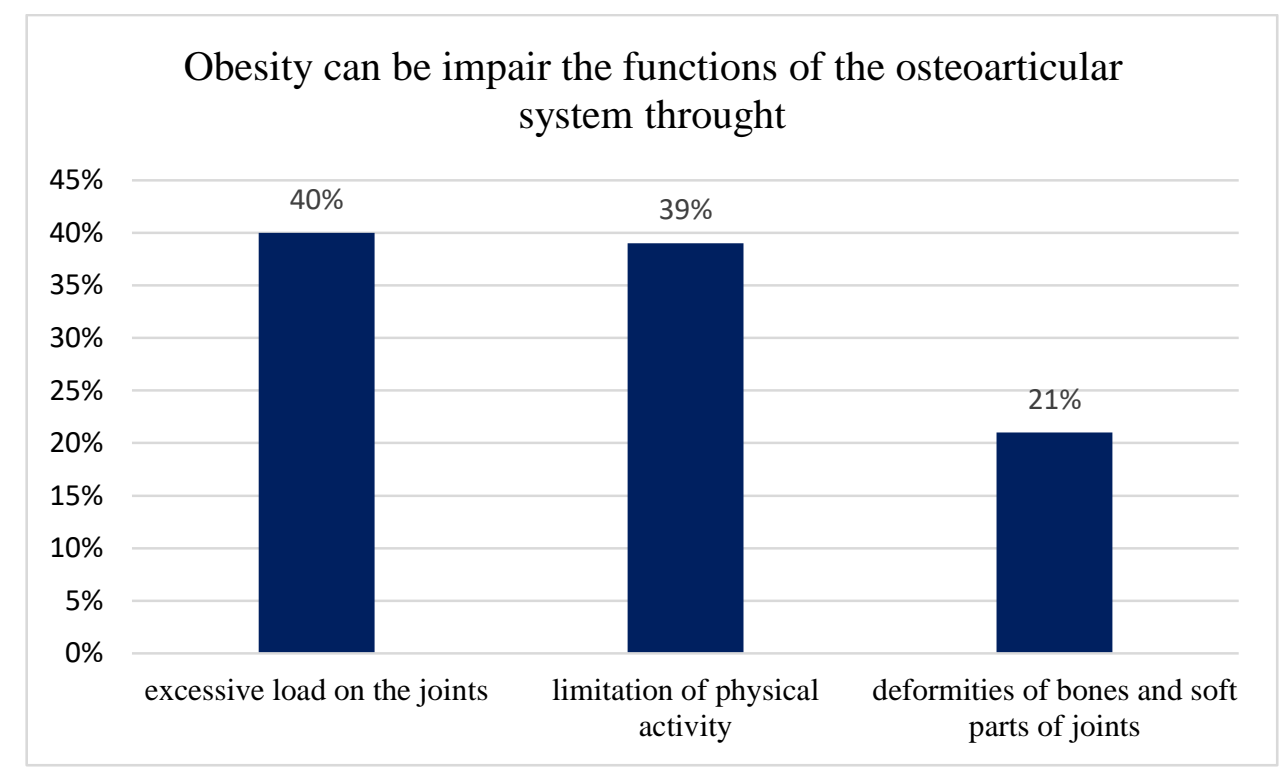

Figure 11. Effects of obesity on the osteoarticular system.

Nearly $40 \%$ of the subjects chose all possible answers, i.e. excessive strain on the joints, impairment of motor activity and deformation of bones and soft parts of the joint. More than $21 \%$ of respondents indicated two answers, while almost $39 \%$ of respondents chose only one ailment. The most frequent choices were excessive load on the joints (97.3\%), impairment of motor activity (57.7\%) and deformation of bones and soft parts of the joint (45\%).

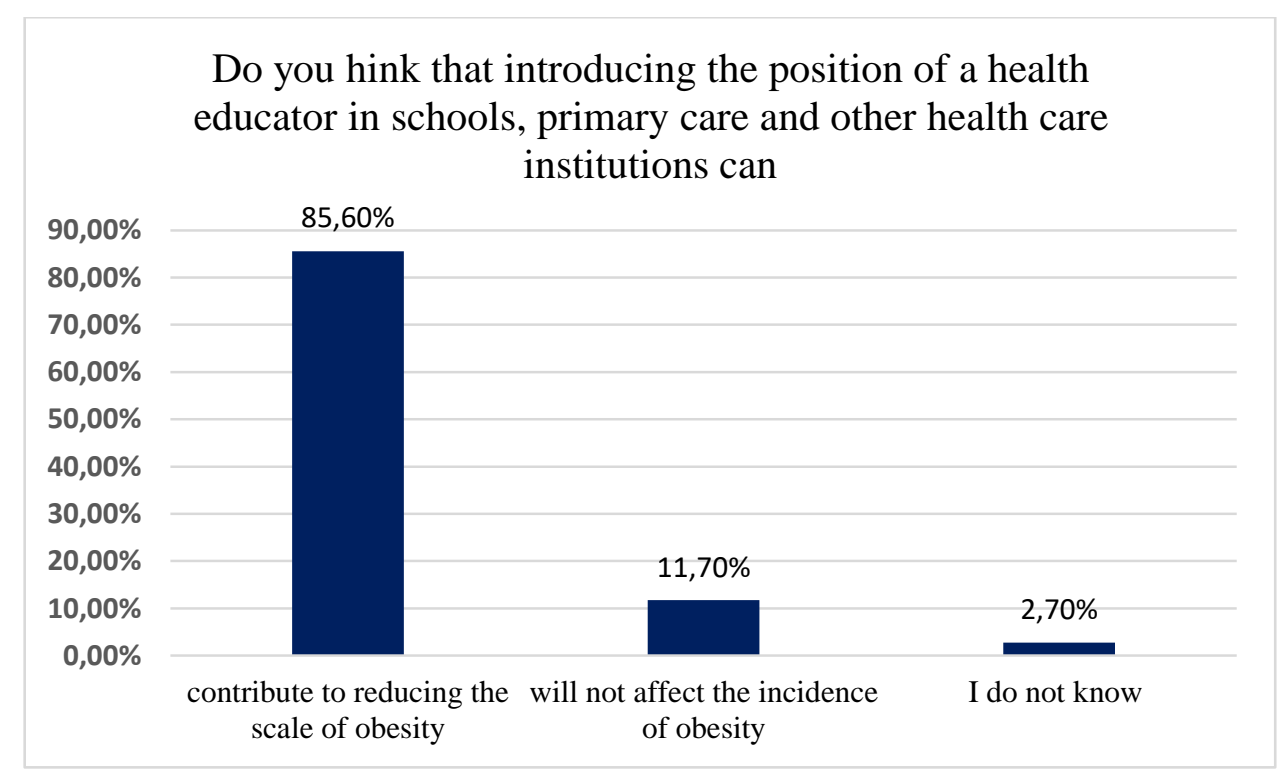

Figure 12 Role of health educator in obesity prevention

This graphic presents answers to the question whether the introduction of a health educator's position in kindergartens, schools, primary health care institutions and other health care institutions will affect the prevalence of obesity. A significant part of students $-85.60 \%$ believe that the position of a health educator in these institutions will contribute to a decrease in the prevalence of obesity, $11.7 \%$ of respondents indicated that it will not affect the prevalence of obesity, $2.7 \%$ did not know the correct answer. 


\section{Discussion}

Obesity, like diabetes, has been recognised by the World Health Organisation as a galloping epidemic of the 21 st century. These are the first non-communicable diseases that have been identified as epidemics. Obesity is a serious medical and economic problem in many countries of the world, both developed and developing economically. It is not only a problem of mature people, but also of children and young people. The effects of this disease have a negative impact on human health, in every aspect, both physical, mental and social.

In the article by Barbara Ślusarska et al. students from the Medical University of Lublin and Jan Kochanowski University in Kielce were examined, 100 people in total. When asked about the BMI value $>30 \mathrm{~kg} / \mathrm{m} 2$, as many as $82 \%$ of the respondents answered correctly that we recognize obesity from this value. In turn, in the own research carried out on a group of 111 people, $64 \%$ of respondents answered that the BMI value from which we recognize obesity is $30 \mathrm{~kg} / \mathrm{m} 2$, the remaining respondents gave an incorrect answer [15].

Then the causes of obesity were asked, in Sen et al. 94\% of students indicated that the basic factor is improper diet, lack of physical activity - 93\%, genetic factors - 84\%, hormonal factors $-74 \%$, taking some drugs $-71 \%$ and advertising - $22 \%$. However, in their own studies, the respondents indicated such factors as: a poor diet and low level of physical activity - $85 \%$, obesity inheritance - 5\%, sign of disease - 4\%, high stress - 3\%, taking drugs - 3\% [16].

The health consequences of obesity were also asked, in Cardialik et al. $96 \%$ of respondents indicated hypertension, $81 \%$ type 2 diabetes, $65 \%$ arthritis, $35 \%$ intestinal and rectal cancer and $14 \%$ mentioned other diseases. On the other hand, in their studies, the students mainly mentioned arterial hypertension - 89\%, ischaemic heart disease - 90\%, strokes - 75\%, infarction $-68 \%$ and atherosclerosis $-78 \%$ [17].

\section{Conclusions}

1. Students have a high knowledge of obesity. A large group of respondents indicated that obesity is not only a disease but also a risk factor for many other disease entities. Students mostly correctly indicate the causes and methods of obesity diagnostics.

2. Students also have sufficient knowledge of the impact of obesity on health. The most frequently mentioned diseases are those related to the cardiovascular and osteoarticular systems. Most students indicated that obesity is a carcinogenic factor.

3. A significant proportion of students claim that the introduction of the position of a health educator in schools, primary health care institutions and other health care units will contribute to halting the growing obesity epidemic among the Polish population. 


\section{References}

1. Taton J., Czech A., Bernas M. Obesity metabolic syndrome. Wydawnictwo Lekarskie PZWL. Warsaw 2007.

2. Wąskowski M., Walicka M., Marcinkowska - Suchowierska E. Obesity - definition, epidemiology, pathogenesis. Postępy Nauk zdrowia 2013; t. XXVI: 301-306.

3. Włodarek D., Lange E., Kozłowska L., Głąbska D. Diet therapy. Wydawnictwo Lekarskie PZWL. Warsaw 2015.

4. https://www.who.int/news-room/fact-sheets/detail/obesity-and-overweight (accessed 2020.05.20)

5.http://www.endokrynologia.viamedica.pl/darmowy_pdf.phtml?indeks=5\&indeks_art=28(accessed: 2020.05.25)

6. Jarosz M, Kłosiewicz-Latoszek L. Obesity. Prevention and treatment. Wydawnictwo Lekarskie PZWL. Warsaw 2009.

7. Sikorska- Wiśniewska G. Overweight and obesity in adolescents. FOOD. Science. Technology. Quality, 2007, 6 (55), 71 - 80.

8. http://www.smartfood.pl/gallery/media/5/phe-2010-3-339.pdf (accessed 2020.05.25)

9.Jarosz M., Bułhak- Jachymczyk B. Human nutrition standards. Basics of obesity and noncommunicable diseases prevention. Wydawnictwo Lekarskie PZWL. Warsaw 2008,2011.

10. Góral R., Tuszewski M. Pathophysiology, clinic and surgical treatment of selected metabolic diseases. Polish Scientific Publishing House. Warsaw - Poznań 1982.

11. Uszyński M. Propedeutics of clinical medicine and public health. University Publishing House of the Ludwik Rydygier Medical Academy. Bydgoszcz 2001.

12. Jaworski P., Binda A., Tarnowski W. Wpływ obtyty na rozwój chorób nowotworowej. Progress of medical sciences 2015; t. XXVIII:674-676.

13. Bąk-Sosnowska M. A place of a psychologist in obesity treatment. Forum of Family Medicine 2009, Volume 3, No. 4, 297-303.

14. Chanduszko-Salska J., Chodkiewicz J. Life satisfaction vs. self-efficacy, social support and health status in overweight and obese women. Endocrinology, Obesity and metabolic disorders 2010, Volume 6, No. 4, 171-178.

15. Ślusarska B., Szcześniak E., Zarzycka D., Dobrowolska B., Zboina B. Knowledge and opinions of students on obesity-related problems. General Medicine and Health Sciences 2014; 54: 229-234.

17. Seń M., Zacharczuk A., Lintowska A. Nutritional behaviour of students of selected Wrocław universities and knowledge about health effects of improper nutrition. Nursing and Public Health 2012; 2: 113-123.

18. Kardjalik K., Bryła M., Maniecka- Bryła I. Nutrition-related health behaviors and the occurrence of overweight and obesity in the group of students. Problems of Hygiene and Epidemiology 2012; 93(1):71-79. 